\title{
Linfoma primário de células $T$ no líquido cefalorraquidiano de cão: relato de caso
}

\author{
[Characterization of primary t-cell lymphoma $(C D 3+)$ in Csf of a dog: case report] \\ L.F. Moraes ${ }^{1}$, F.G. Romão ${ }^{1}$, A.S. Borges ${ }^{2}$, R.K. Takahira ${ }^{2}$, F.B. Souza ${ }^{3}$, \\ R.L. Amorim ${ }^{2}$, L.C. Vulcano ${ }^{2}$ \\ ${ }^{1}$ Aluno de pós-graduação - Faculdade de Medicina Veterinária e Zootecnia - UNESP-Botucatu, SP \\ ${ }^{2}$ Faculdade de Medicina Veterinária e Zootecnia - UNESP-Botucatu, SP \\ ${ }^{3}$ Médico veterinário autônomo
}

\begin{abstract}
RESUMO
Relata-se o diagnóstico de linfoma primário no sistema nervoso central em um cão Labrador Retrievier, de 10 anos de idade, que apresentava episódios convulsivos, incoordenação nos membros posteriores, head tilt, ataxia e sensibilidade diminuída no lado esquerdo. Constataram-se alterações laterais esquerdas, como ausências de propriocepção e de posicionamento tátil, alterações posteriores nas provas de carrinho de mão e de reação ao pulo e diminuição da extensão da postura e hemilocomoção. No líquido cefalorraquidiano (LCR), houve predomínio de linfócitos atípicos, caracterizados pela presença de anisocitose e anisocariose, nucléolos evidentes e anisonucleose, basofilia e microvacuolização citoplasmáticas, mitoses atípicas e corpúsculos linfoglandulares, compatíveis com linfoma, confirmado pelo exame histológico e imunocitoquímico, o qual revelou origem $\mathrm{T}$, com expressão $\mathrm{CD} 3+$ e CD79-. A tomografia computadorizada não foi conclusiva e evidenciou diversas áreas hipodensas e intensificação de contraste na região de sulcos e giros do parênquima encefálico. A coleta do LCR foi essencial na rapidez do diagnóstico definitivo, indicando a natureza rara desta lesão primária.
\end{abstract}

Palavras-chave: cão, linfoma, liquor, sistema nervoso central, neoplasia primária

\begin{abstract}
A primary lymphoma in the central nervous system in a 10 year-old Labrador Retriever presenting seizures, hind limb incoordination, head tilt, ataxia and decreased sensitivity on the left side was reported. Regarding postural reactions, there were changes in the left side such as proprioceptive and tactile positioning defects, and in the posterior reaction tests such as wheelbarrowing and limb hopping, along with a reduction in the extensor postural thrust reaction and hemi-walking response. A cerebrospinal fluid (CSF) analysis showed a predominance of atypical lymphocytes characterized by pleocytosis, marked anisocytosis and anisokaryosis, evident nucleoli and anisonucleosis, cytoplasmic basophilia and microvacuolation, atypical mitotic figures and lymphoglandular bodies. These findings were compatible with lymphoma, which was confirmed by histopathology and immunocytochemistry that showed a T-cell origin, with CD3 + and CD79-expression. A computed tomography scan was inconclusive and showed several hypodense areas and a contrast enhancement in the sulci and gyri region of the brain parenchyma. The CSF analysis was essential for a quicker definitive diagnosis, indicating the nature of this rare primary injury.
\end{abstract}

Keywords: dog, lymphoma, cerebrospinal fluid, central nervous system, primary neoplasia

\section{INTRODUÇÃO}

Neoplasias do sistema nervoso central (SNC) são causas comuns de disfunção neurológica em animais. Relata-se a ocorrência de 14,5 casos

Recebido em 25 de julho de 2011

Aceito em 10 de maio de 2012

E-mail: liviafm@gmail.com para cada 100.000 cães (O’Brien e Axlund, 2005; Synder et al., 2008). Sinais neurológicos resultantes de neoplasias cerebrais dependem, primariamente, da localização, do tamanho e da velocidade de crescimento da massa tumoral (Lecouteur, 2003). As lesões podem ser solitárias ou múltiplas, difusas nas leptomeninges, 
periventriculares, vítreas ou em medula espinhal intradural (Bellesso et al., 2008).

Linfomas que envolvem o SNC são comumente relacionados como parte de processos multicêntricos ou sistêmicos, com frequente e extensiva infiltração do plexo coroide e leptomeninges, e raramente são observados como uma neoplasia primária. O linfoma cerebral primário é resultante da transformação neoplásica dos linfócitos do SNC e geralmente é único. Quando atinge as leptomeninges, é possível observar células mononucleares plasmocitoides atípicas no líquido cefalorraquidiano (LCR) em cães (Long, 2001; O'Brien e Axlund, 2005; Long, 2006). $\mathrm{O}$ envolvimento meníngeo em humanos, caracterizado por células neoplásicas no LCR ou nódulos em raízes nervosas, ocorre em $25 \%$ dos casos de linfoma primário do sistema nervoso central. Em menos de $1 \%$ dos casos há envolvimento primário da medula espinhal (Bellesso et al., 2008). Em cães, 70 a $75 \%$ dos linfomas são de células $\mathrm{B}, 20$ a $25 \%$ são de células $\mathrm{T}$ e menos de $5 \%$ são classificados como não T e não B (Morrison, 2005).

A análise do LCR ou liquor é recomendada, pois os resultados podem auxiliar na exclusão de casos de doenças inflamatórias e como suporte no diagnóstico de neoplasias cerebrais, sendo mais sensível para detecção de processos inflamatórios (Lecouteur, 2003; Bohn et al., 2006).

Neste relato, descreve-se o caso raro de um cão com linfoma primário do $\mathrm{SNC}$, diagnosticado pela análise do liquor, destacando-se a importância deste exame laboratorial e as particularidades histológicas.

\section{CASUÍSTICA}

Uma cadela Labrador Retriever, não castrada, com 10 anos de idade, foi atendida em Hospital Veterinário Escola com histórico de três episódios convulsivos há um mês e fraqueza nos membros posteriores há cinco dias. $\mathrm{O}$ animal vive em ambiente rural, não possui contactantes e apenas a vacinação antirrábica está atualizada. $\mathrm{O}$ proprietário relatou, ainda, aumento de sensibilidade na região coxofemoral e dificuldade de locomoção não progressiva, de início aguda, por três dias.
Ao exame neurológico, o animal encontrava-se alerta, com postura normal, entretanto apresentava rotação lateral direita da cabeça (head tilt), ataxia, sensibilidade diminuída no lado esquerdo e incoordenação de posteriores. Em relação às reações posturais, constataram-se alterações laterais esquerdas, como ausência de propriocepção e de posicionamento tátil, alterações posteriores nas provas de carrinho de mão e de reação ao pulo, além de uma diminuição da extensão da postura e hemilocomoção.

$\mathrm{Na}$ avaliação dos nervos cranianos, o animal apresentou uma diminuição da sensibilidade facial esquerda e nistagmo posicional horizontal. Durante o exame físico, não foi constatada nenhuma outra alteração, e o animal apresentava um bom estado geral.

Os diagnósticos provisórios incluíram condições de síndrome vestibular central (neoplasia ou traumática). Foram solicitados como exames complementares hemograma, dosagens de ureia, creatinina, alalina aminotransferase (ALT), fosfatase alcalina (FA), proteínas totais séricas, albumina, colesterol, triglicérides, análise de LCR e tomografia computadorizada (TC). Não foram observadas alterações no hemograma, assim como nos exames bioquímicos. Foram coletados $3 \mathrm{~mL}$ de LCR com coloração xantocrômica, de aspecto turvo, com coagulação negativa e densidade de 1,018. Ao exame químico, constatou-se $\mathrm{pH} 7,5$, proteínas 246,6mg/dL, glicose negativa, sangue oculto e pandy positivos (4+ e $3+$, respectivamente).

$\mathrm{Na}$ contagem total de células, foram encontradas 410 hemácias/ $\mu \mathrm{L}$ e 3.880 células nucleadas $/ \mu \mathrm{L}$. Ao exame citológico, houve um predomínio de linfócitos atípicos $(82 \%)$, seguidos de pequenos linfócitos (9\%), neutrófilos segmentados $(5 \%)$ e macrófagos $(5 \%)$. Os linfócitos atípicos foram assim caracterizados devido à presença de anisocitose e aniocariose, nucléolos evidentes e anisonucleose, basofilia e microvacuolização citoplasmáticas, mitoses atípicas e corpúsculos linfoglandulares, compatíveis com linfoma. Também foram observadas eritro e leucofagocitose, bem como hemácias livres e íntegras. Após o diagnóstico, foi solicitado um exame imunocitoquímico do LCR, que o classificou em linfoma de células $\mathrm{T}(\mathrm{CD} 3+\mathrm{e}$ CD79-). 
Foi realizado um exame tomográfico de encéfalo com cortes axiais de $3 \times 3 \mathrm{~mm}$ na região supratentorial e de $2 \mathrm{X} 2 \mathrm{~mm}$ na fossa posterior nas fases pré e pós-administração de meio de contraste intravenoso iodado iônico (Reliev® dose: $2 \mathrm{~mL} / \mathrm{kg}$ ). A técnica empregada utilizou 120 de quilovoltagem e 160 de miliamperagem. O parênquima encefálico apresentou-se discretamente heterogêneo, com presença de diversas áreas hipodensas (densidade: 4 - 24 unidades Hounsfield), sem captação de contraste e com limites parcialmente definidos, medindo $0,5 \mathrm{~cm}$ de diâmetro, localizados em região periférica (predominantemente em lobos parietais). Também foi evidenciada intensificação de contraste na região de sulcos e giros do parênquima encefálico, o que sugere infiltrado neoplásico (Fig. 1).

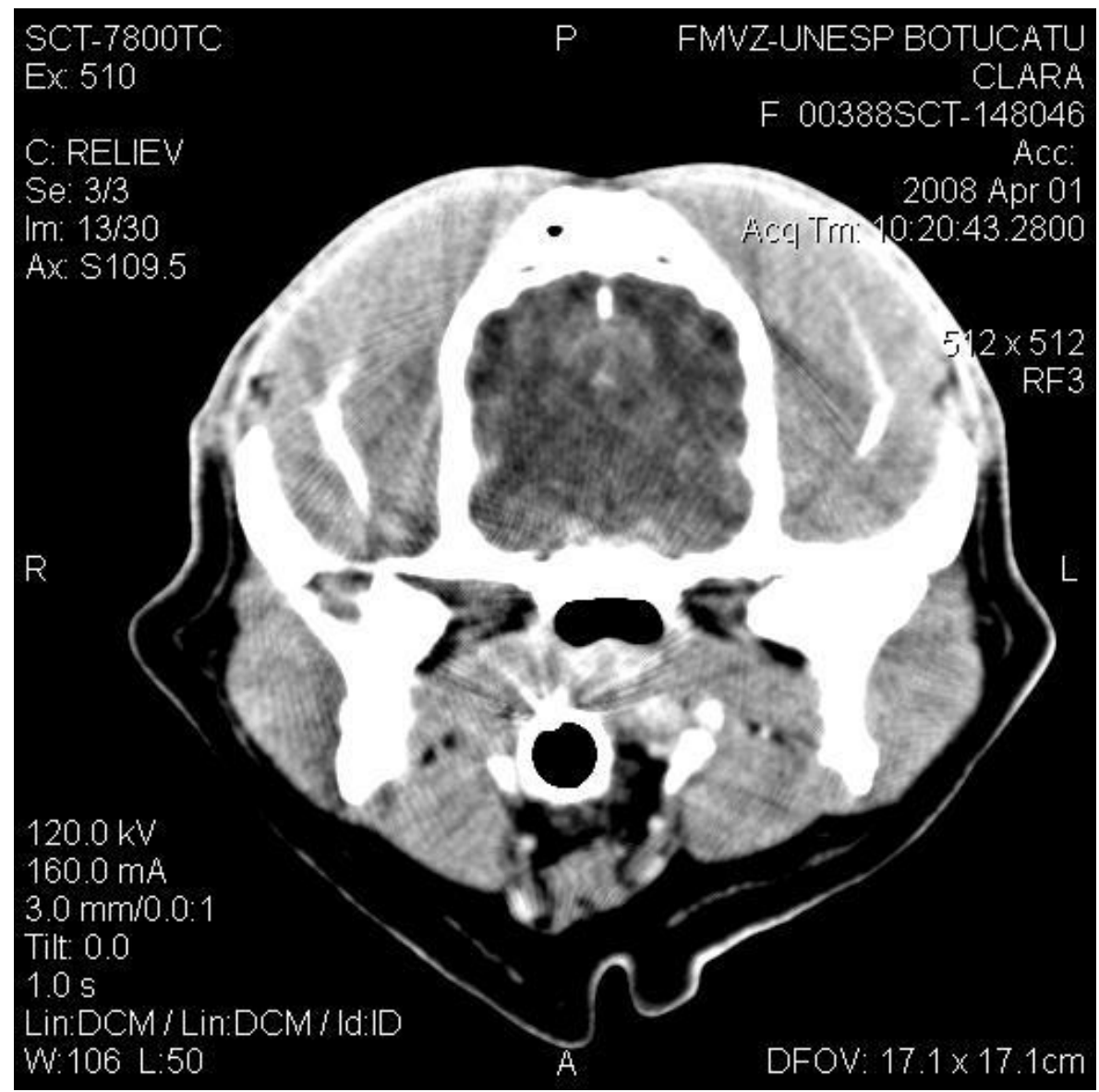

Figura 1. Cão. Exame tomográfico do encéfalo evidenciando parênquima discretamente heterogêneo, presença de diversas áreas hipodensas, sem captação de contraste e com limites parcialmente definidos. Intensificação de contraste na região de sulcos e giros do parênquima encefálico. Fonte: Serviço de Radiologia e Ultrassonografia da FMVZ - UNESP, Botucatu, SP.

O animal foi submetido à eutanásia no mesmo dia e, no relatório de necropsia, foram descritas as seguintes alterações: congestão moderada de cérebro, dilatação cardíaca e hipertrofia de ventrículo esquerdo, endocardiose de válvulas atrioventriculares direita e esquerda, abaulamento esplênico, fibrose hepática, gastrite aguda com úlcera de $0,5 \times 0,5 \mathrm{~cm}$ de diâmetro, pólipo em mucosa gástrica, enterite catarro- hemorrágica e pólipos em mucosa duodenal, além de congestão moderada em rins, nefropatia crônica e cistite hemorrágica. Não havia evidências macroscópicas de neoplasias primárias ou envolvimento secundário em outros órgãos.

No exame histológico do SNC, foram realizados cortes do córtex frontal, parietal, occipital e 
cerebelo, evidenciando infiltração de células linfoides com características neoplásicas que comprometiam as meninges acompanhando todo o trajeto vascular e contornando os giros cerebrais. Em algumas áreas, houve infiltração periférica à parede dos vasos. Estas células apresentavam tamanho médio e citoplasma escasso, anisocariose e pleomorfismo acentuado, núcleo redondo, cromatina frouxa e nucléolos grandes, múltiplos e periféricos, compatíveis com linfoma pleomórfico de células T. Notaramse, ainda, figuras de mitose (Fig. 2). Também foi realizada a imunoistoquímica do cerebelo e das regiões parietal, frontal e occiptal do cérebro, confirmando o diagnóstico de linfoma de células $\mathrm{T}$ (CD3 positivo).

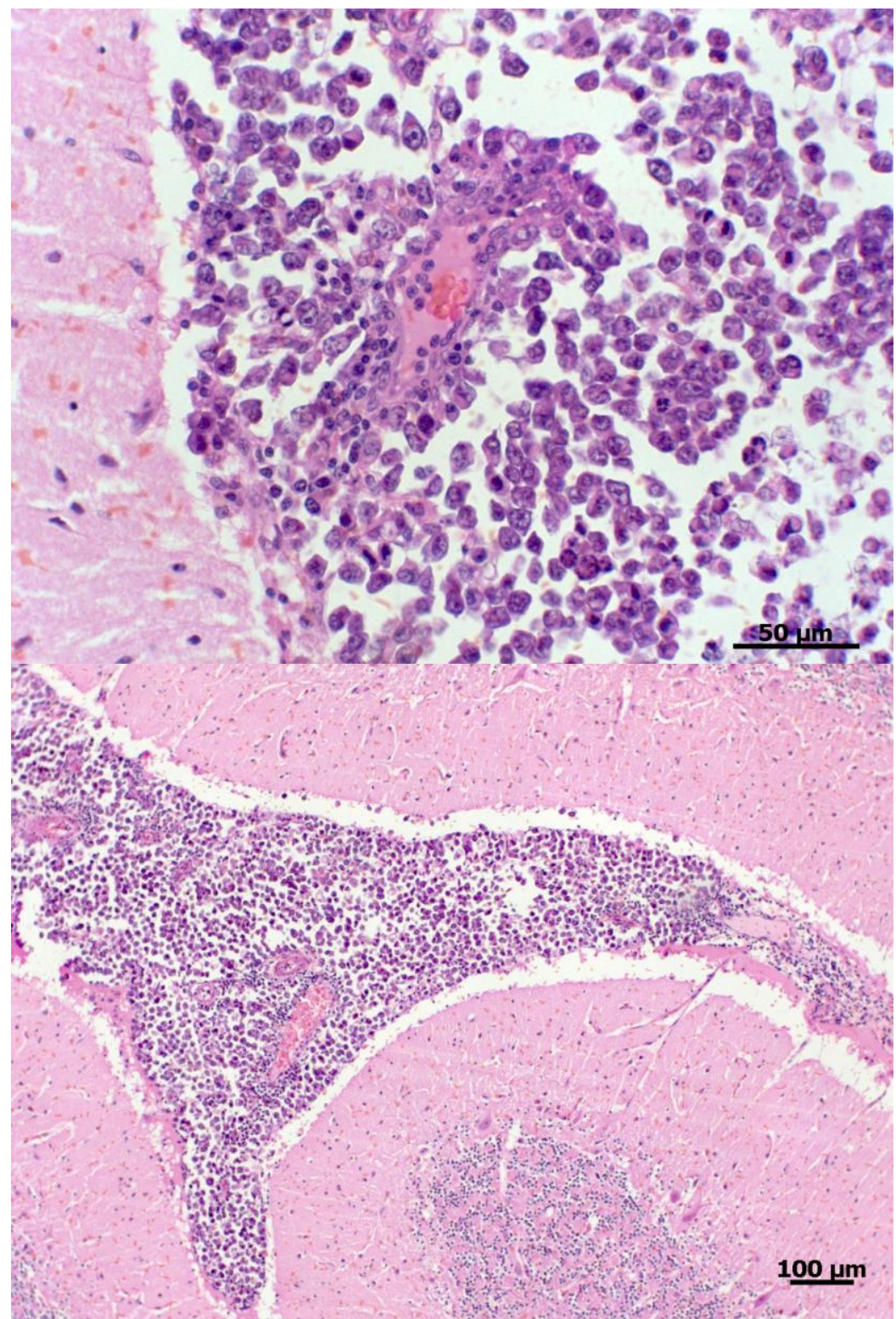

Figura 2. Cão. Exame histopatológico do córtex cerebral. Corte histológico de córtex cerebral evidenciando infiltração de células linfoides com características neoplásicas, tamanho médio e citoplasma escasso, anisocariose e pleomorfismo acentuado, núcleo redondo, cromatina frouxa, acompanhando todo o trajeto vascular e contornando os giros cerebrais. Aumento de 100 e 400X. Fonte: Serviço de Patologia da FMVZ - UNESP, Botucatu, SP. 


\section{DISCUSSÃO E CONCLUSÕES}

Os relatos de linfoma em cães de raça definida sugerem uma relação genética, e algumas raças, como Golden Retriever e Boxer, são citadas como predispostas a desenvolverem linfoma cerebral (Morrison, 2005; Synder et al., 2006). Synder et al. (2006) ainda incluíram Doberman, Scottish Terrier e Old English Sheepdog como raças de maior risco para desenvolvimento de linfomas cerebrais. Neste caso, além da predisposição racial, o animal apresentava idade compatível com a faixa etária de maior ocorrência, pois os tumores cerebrais são mais frequentes em animais mais velhos, acima de cinco anos de idade, com média de 9,5 anos (O’Brien e Axlund, 2005; Synder et al., 2006).

As alterações clínicas neurológicas observadas neste caso provavelmente decorreram da infiltração nos tecidos cerebrais normais, compressão de estruturas adjacentes, alteração da circulação e necrose local. Alterações secundárias relacionadas à presença de neoplasias cerebrais podem incluir hidrocefalia, aumento de pressão intracraniana, edema e herniação cerebral (Lecouteur, 2003; O’Brien e Axlund, 2005).

Neoplasias intracranianas secundárias são mais comuns que as neoplasias primárias, relacionadas à metástase via hematógena, atingindo principalmente cérebro e cerebelo (O'Brien e Axlund, 2005; Synder et al., 2008). Na maioria dos casos, mais de uma região anatômica do cérebro está envolvida, resultando em sinais multifocais (Synder et al., 2006), observados neste relato, entretanto esta neoplasia foi classificada como primária de acordo com as evidências em necropsia e histopatológicas. As neoplasias primárias no SNC são raras e, portanto, pouco relatadas na medicina veterinária. Long et al. (2001) relataram um caso semelhante. Em humanos, a lesão intracraniana única é a apresentação mais comum em imunocompetentes (Bellesso et al., 2008).

Os sinais clínicos relacionados a tumores do SNC geralmente são inespecíficos e dependem da localização da lesão, incluindo convulsões, principalmente se a primeira surgir após os quatro anos de idade, além de alteração mental, déficit de nervos cranianos, paresias, alterações de comportamento, andar em círculos e disfunção endócrina. O déficit dos nervos cranianos observado neste relato pode ser relacionado à infiltração neoplásica direta ou como parte de uma polineuropatia paraneoplásica (Long et al., 2001).

Neoplasias de crescimento lento permitem uma adaptação ao aumento da pressão intracraniana, no entanto, quando estes mecanismos compensatórios forem exauridos, os sinais clínicos podem progredir rapidamente. Esta situação foi observada neste caso, pois os sinais iniciaram um mês antes do diagnóstico e das alterações clínicas mais evidentes. Neoplasias de crescimento rápido não permitem esta adaptação, e os sinais clínicos são agudos (O'Brien e Axlund, 2005).

Processos inflamatórios e neoplásicos não podem ser diferenciados apenas pela pleocitose, pois valores acima de 500 células $/ \mu \mathrm{L}$ podem ser associados à necrose e ao envolvimento das meninges, mesmo em condições neoplásicas. Células neoplásicas raramente são observadas no LCR, exceto no linfoma e meningioma, e podem refletir o envolvimento das meninges. A ausência de linfoblastos no LCR não exclui a possibilidade de linfoma, e a alteração citológica mais comum em neoplasias intracranianas primárias é a pleocitose mista (Chrisman, 1992; Bohn et al., 2006; Synder et al., 2006), confirmada neste relato.

Existem diferentes resultados quanto ao diagnóstico de linfoma cerebral do LCR. Para O'Brien e Axlund (2005), em 100\% dos casos é possível diagnosticar o linfoma pelo LCR, no entanto Synder et al. (2006) observaram atipia celular ou células neoplásicas em apenas dois de seis casos diagnosticados. As características do LCR em cães com linfoma incluem aumento de contagem de leucócitos e proteínas, sendo 90 a 95\% de linfócitos atípicos (Aptekmann et al., 2005), porcentagem próxima à observada neste caso (82\%). No estudo de Bohn et al. (2006), no grupo dos cães com neoplasia cerebral, pode-se confirmar na citologia o diagnóstico de linfoma no cão que apresentou a maior pleocitose. Outros dois cães não apresentaram pleocitose, entretanto foram evidenciadas células atípicas na citologia.

A elevação da proteína no LCR observada neste caso pode ocorrer devido à alteração na barreira hematoencefálica, necrose local, interrupção do 
fluxo e absorção normais de LCR ou como resultado do aumento da produção local de imunoglobulinas (Chrisman, 1992; Bohn et al., 2006).

A identificação do tipo celular por imunofenotipagem é importante para determinar o prognóstico e tornou-se um passo relevante na classificação do linfoma e na relação entre alteração biológica e resposta à terapia (Couto et al., 1984). Anticorpos marcados com CD3 e CD79 demonstram a reação cruzada com linfócitos T e B, respectivamente (Milner et al., 1996). A imunocitoquímica do LCR auxilia no diagnóstico diferencial entre linfoma e processos inflamatórios do SNC e no diagnóstico e tratamento precoces dessa doença (Long, 2001).

No estudo de Fournel-Fleury et al. (2002), após a imunofenotipagem de 146 casos de cães com linfoma, 32,8\% (46 casos) foram classificados como linfomas de células $\mathrm{T}$ e a idade média dos animais foi de 6,9 anos. De acordo com a classificação de Kiel, adaptada para a espécie canina, a maioria desses casos, assim como este relato, enquadra-se como linfomas de "alto grau", pleomórficos, com variação no tamanho celular $(43,5 \%)$, ou linfoma linfoblástico. Além da imunofenotipagem por meio da utilização de CD3 e CD79 como marcadores, considerou-se também a morfologia celular como critério de classificação.

Linfomas linfoblásticos de células $\mathrm{T}$ são morfologicamente difíceis de serem distinguidos da forma equivalente aos linfomas tipo B. No entanto, na prática, pode-se presumir que são fenotipicamente T, já que a sua frequência é alta, assim como em humanos, chegando a $90 \%$ (Fournel-Fleury et al., 2002).

Linfomas linfoblásticos $\mathrm{T}$, de rápida evolução, atingem cães com idade média mais baixa, evidenciando com frequência invasão mediastínica e de medula óssea, caracterizada por proliferação de células mononucleares de tamanho médio, cromatina fina e discretos nucléolos, duplamente positivos ou negativos para CD4 e CD8, podendo ser facilmente comparados com casos humanos e muito mais frequentes que os de origem B (Fournel-Fleury et al., 2002). O prognóstico do linfoma T é pior que o do linfoma de origem B (Aptekmann et al., 2005).

A TC produz imagens menos acuradas para detecção de massas intracranianas se comparada com a ressonância magnética (RM) (Synder et al., 2006). Esta superioridade da RM é observada nos casos de edema, cistos, alteração da vascularização, hemorragias e necrose. Lesões logo abaixo do crânio ou com espaços reduzidos, envoltas por ossos espessos e irregulares, são mais bem delimitadas pela RM, embora a TC e a $\mathrm{RM}$ produzam imagens seccionadas muito similares (Morozumi et al., 1997; O’Brien e Axlund, 2005). No estudo comparativo de Polizopoulou et al. (2004) entre as técnicas de TC e RM, houve sensibilidade similar entre elas, correlacionando as alterações de imagem com os achados histopatológicos.

Existem poucos relatos em cães de linfoma primário em sistema nervoso central. Este caso merece destaque em razão da ausência de alterações macroscópicas à necropsia e da peculiaridade do trajeto das células neoplásicas que contornam os giros cerebrais, comprometendo as meninges e acompanhando todo o trajeto vascular, sendo que, em algumas áreas, houve uma infiltração periférica à parede dos vasos. A coleta do LCR foi essencial no diagnóstico definitivo com maior rapidez, já que a imagem da TC não foi conclusiva. A análise do LCR não é capaz de localizar a lesão neurológica, mas é de extrema importância para indicar sua natureza. O linfoma é uma neoplasia com característica esfoliativa, facilitando $\mathrm{o}$ diagnóstico por meio de efusões abdominais, pericárdicas ou pleurais, além do LCR, facilmente identificado por um patologista clínico.

Para o diagnóstico definitivo dos linfomas cerebrais em cães, além da suspeita clínica, é essencial um conjunto de informações provenientes da análise do LCR, exame por imagem, e, quando possível, a imunofenotipagem, capaz de direcionar de forma mais específica a conduta terapêutica e com melhor definição do prognóstico.

\section{AGRADECIMENTOS}

À FMVZ - Unesp Botucatu SP, pelo apoio. 


\section{REFERÊNCIAS}

APTEKMANN, K.P.; OKAMOTO, C.E.; CAMPOS, K.C.H. et al. Multicentric lymphoma with metastasis in the central nervous system in a dog. Arq. Bras. Med. Vet. Zootec., v.57, p.307311, 2005.

BELLESSO, M.; BIZZETTO, R.; PEREIRA, J. et al. Linfoma primário do sistema nervoso central. Rev. Bras. Hematol. Hemoter., v.30, p.54-60, 2008.

BOHN, A.A.; WILLS, T.B.; WEST, C.L. et al. Cerebrospinal fluid analysis and magnetic resonance imaging in the diagnosis of neurologic disease in dogs: a retrospective study. Vet. Clin. Pathol., v.35, p.315-320, 2006.

CHRISMAN, C.L. Cerebrospinal fluid analysis. Vet. Clin. N. Am.: Small Anim. Pract., v.22, p.781-810, 1992.

COUTO, C.G.; CULlEN, J.; PEDROIA, V. et al. Central nervous system lymphosarcoma in the dog. J. Am. Vet. Med. Assoc., v.184, p.809-813, 1984.

FOURNEL-FLEURY, C.; PONCE, F.; FELMAN, P. et al. Canine T-cell lymphomas: a morphological, immunological, and clinical study of 46 new cases. Vet. Pathol., v.39, p.92109, 2002.

LECOUTEUR, R.A. Diagnosis and Treatment of Brain Tumors. Disponível em: $<$ http://www.vin.com/proceedings/Proceedings.p 1x?CID=WSAVA2002\&PID=2631>. Acessado em: 20 ago. 2010

LONG, S.N.; JOHNSTON, P.E.J.; ANDERSON, T.J. Primary T-cell lymphoma of the central nervous system in a dog. J. Am. Vet. Med. Assoc., v.218, p.719-722, 2001.
LONG, S. Neoplasia of the Nervous System In: Braund, K.G. (Ed.) Clinical neurology in small animals: localization, diagnosis and treatment., Ithaca: International Veterinary Information Service, Ithaca NY, 2006. Disponível em: http://www.ivis.org/advances/Vite/braund26/cha pter.asp?LA=1. Acessado em: 20 ago. 2010.

MILNER, R.J.; PEARSON, J.; NESBIT, J.W. et al. Immunophenotypic classification of canine malignant lymphoma on formalin-fixed paraffin wax-embedded tissue by means of CD3 and CD79a cell markers. J. Vet. Res., v.19, p.309313, 1996.

MOROZUMI, M.; MIYAHARA, K.; SATO, M. et al. Computed tomography and magnetic resonance findings in two dogs and a cat with intracranial lesions. J. Vet. Med. Sci., v.59, p.807-810, 1997.

MORRISON, W.B. Mediations on lymphoma in dogs and cats. Proceeding of the NAVC - North American Veterinary Conference, January 8-12, 2005, Orlando, Florida. Reprinted in the IVIS website with the permission of the NAVC http://www.ivis.org/ Disponível em: <http://www.ivis.org/proceedings/navc/2005/SA E/269.pdf?LA=1>. Acessado em: 20 ago. 2010

O'BRIEN, D.P.; AXLUND, T.W. Brain disease. In: ETTINGER, S.J. (Ed). Textbook of Veterinary Internal Medicine. 6nd ed. St. Louis, Missouri: Elsevier Saunders, 2005. p.803-835.

POLIZOPOULOU, Z.S.; KOUTINAS, A.F.; SOUFTAS, V.D. et al. Diagnostic correlation of CT-MRI and histopathology in 10 dogs with brain neoplasms. J. Vet. Med., v.51, p.226-231, 2004.

SYNDER, J.M.; LIPITZ, L.; SKORUPSKI, K.A. et al. Secundary intracranial neoplasia in the dog: 177 cases (1986-2003). J. Vet. Intern. Med., v.22, p.172-177, 2008

SYNDER, J.M.; SHOFER, F.S.; VAN WINKLE, T.J. et al. Canine intracranial primary neoplasia: 173 cases (1986-2003). J. Vet. Intern. Med., v.20, p.669-675, 2006. 